\title{
RELACIONES SOCIALES DE MUJERES AYMARA TRANSLOCALES: UNA EXPLICACIÓN DESDE LA PRESENCIA/AUSENCIA DEL SUMA QAMAÑA
}

\author{
SOCIAL RELATIONS OF AYMARA TRANSLOCAL WOMEN: AN EXPLANATION \\ FROM THE PRESENCE/ABSENCE OF “SUMA QAMAÑA”
}

Adimelia Moscoso García*, María Vásquez Acosta** y Cristóbal Pulido Iparraguirre ${ }^{* * * *}$

\begin{abstract}
Este artículo demuestra la presencia del Suma Qamaña en las relaciones de mujeres Aymara translocales de la Región de Tarapacá y es mediante las historias de vida de las entrevistadas que se observa la influencia del Suma Qamaña en sus relaciones. Desde un marco metodológico del paradigma de investigación indígena, se relevan las vicisitudes de ser mujer Aymara translocal en contextos sociales y culturales diferentes. El resultado principal de esta investigación es la presencia intermitente de los principios del Suma Qamaña en la vida: primero, una fuerte presencia del Suma Qamaña; luego, un distanciamiento del mismo y, posteriormente, el reencuentro con su idiosincrasia.

Se concluye que las interacciones de estas mujeres se ven fuertemente influidas por las relaciones que establecen con los "otros" y con la institucionalidad chilena. En cada momento se evidencian afectos, sentimientos, emociones y sensaciones, que definen y enmarcan la experiencia de ellas.
\end{abstract}

Palabras claves: Suma Qamaña, paradigma indígena, mujer Aymara, translocal.

This article demonstrates the presence of Suma Qamaña in the relationships of the translocal Aymara woman in the region of Tarapacá. Through the life stories of the interviewees, the influence of Suma Qamaña in their relationships is observed. From a methodological framework of the indigenous research paradigm, the vicissitudes of being a Translocal Aymara Woman in different social and cultural contexts are surveyed. The main result of this investigation is the intermittent presence of the principles of Suma Qamaña in life. First a strong presence of Suma Qamaña, then a distancing from him and later the reunion with his idiosyncrasy. It is concluded that the interactions of these women are strongly influenced by the relationships they establish with "others", and the Chilean institutional framework. At every moment, affections, feelings, emotions and sensations are evident, which define and frame the experience.

Key words: Suma Qamaña, indigenous paradigm, Aymara Woman, translocal.

\section{Introducción}

\section{¿Qué es el Suma Qamaña?}

No hay una traducción que logre dar cuenta del significado de Suma Qamaña, de la lengua Aymara. Albó (2009) hace una extensa revisión de este concepto y sugiere la utilización del concepto "vivir bien" para dar cuenta de su sentido. Huanacuni (2010) sostiene que un mejor significado sería vida en plenitud: saber vivir en armonía o en permanente respeto y equilibrio respecto de los ciclos de la madre tierra, el cosmos y con toda forma de existencia, por medio de la comprensión de que todo está interconectado. Gudynas (2009) agrega que se caracteriza por ser histórico, holístico, dinámico, sistémico, relacional e integrador del ser humano, donde todo está interrelacionado $\mathrm{y}$ es interdependiente ${ }^{1}$.

Por más de quinientos años la identidad cultural del pueblo Aymara ha resistido y se aferra a la idea del Suma Qamaña. Esquivel (2013) propone como principios fundamentales del "buen vivir" la armonía, la complementariedad, la reciprocidad, la dualidad, la relacionalidad, la ciclicidad y la correspondencia (p. 03). Así, estos serían el eje relacional de quienes viven según los principios del Suma Qamaña, además agrega que son un legado que ha pasado de las abuelas y ancestros de las familias a las comunidades.

\footnotetext{
* Psicóloga. Iquique, Chile. Correo electrónico: adimelia.mg@gmail.com

** Psicóloga. Iquique, Chile. Correo electrónico: mariaolgavasquezacosta@gmail.com

*** Departamento de Ciencias Sociales y Jurídicas, Universidad de Tarapacá. Iquique, Chile.

Correo electrónico: cpulido@academicos.uta.cl
} 


\section{Suma Qamaña y cosmovisión andina: un entramado de significados}

El Suma Qamaña encuentra concepciones similares en otros pueblos indígenas, como por ejemplo en los mapuches que hablan de Kume Morgen, los quechuas de Sumak Kawsay, los guaraníes de Nande Reko, los achuares del Shiir Waras; es así como en muchos pueblos esta idea del "buen vivir" o "vivir en plenitud" encuentra su eco. Desde el Suma Qamaña, los pueblos indígenas originarios promueven el vivir con responsabilidad desde la complementariedad y la reciprocidad. Como el Ayni ${ }^{2}$, que implica la conciencia y la convicción de que la primera responsabilidad es con la madre tierra y el cosmos; la segunda responsabilidad es con la comunidad; la tercera con la pareja y, por último, la responsabilidad con uno mismo. Por ello, Huanacuni (2010) considera que dentro del Suma Qamaña hay una preocupación por los derechos colectivos. Este concepto cobra relevancia y visibilidad en la formalización de las nuevas Constituciones de Bolivia y Ecuador (Gudynas y Acosta 2011). En Chile, aún no hay una consideración directa o indirecta en la Constitución (Ribadeneira, 2020), hoy perdura en la vida de muchos Aymara. Por lo indicado, la presente investigación tiene por objetivo demostrar la presencia del Suma Qamaña en las relaciones de las mujeres Aymara translocales ${ }^{3}$ de la Región de Tarapacá, enfatizando el hecho de ser mujer en la actualidad. Así, mediante historias de vidas y en un marco metodológico del paradigma de investigación indígena, se revisa cómo los principios del Suma Qamaña rigen la vida de estas mujeres.

Los Aymara habitan en tres zonas del norte de Chile: en la Región de Arica y Parinacota, en la Región de Tarapacá y, en una menor proporción, en la Región de Antofagasta que corresponde a 156.754 personas. En una revisión bibliográfica, se pueden encontrar estudios, desde diferentes diciplinas y temáticas, que aportan a la comprensión de los aspectos de la vida de este pueblo originario como los escritos de Vivian Gavilán, Ana María Carrasco, Sergio González, entre otros más, que dan cuenta de prácticas que tienen continuidad y vigencia yendo más allá de las relaciones de subordinación con los Estados (Gundermann 2018; Carrasco y González 2014; Díaz y Tapia 2013; Gundermann y González 2008). Y el ejemplo más discutido es la precipitada declaración que emerge en los años 80 por Van Kessel, en la que anunció:
El holocausto como autoeliminación, y como etnosuicidio. Sería el caso del abandono, general y total, de las raíces, cosmovisión y cultura Aymaras, con el propósito de participar en los bienes materiales mayores que después de haber estrangulado el sistema andino les ofrece el sistema de la sociedad de Occidente (p. 313).

Lo anterior permite aseverar que si bien los Aymara del norte de Chile forman parte de la riqueza histórica y cultural del amplio "mundo andino", han sufrido los efectos de estos procesos históricos, por esta razón, la cultura Aymara actualmente solo es un ápice de lo que fue la matriz andina original. Sin embargo, pese a los cambios sufridos y a sus amplias consecuencias en la vida y cultura de este pueblo, ciertas prácticas y principios se han mantenido entre las mujeres Aymara de las regiones del norte de Chile.

En las comunidades Aymara perduran elementos propios de una tradición cultural altiplánica transmitidos mediante la organización colectiva y se advierten prácticas ancestrales propias de este pueblo que permanecen hasta la actualidad (Valdivia 2006), que despliegan sus alas como el cóndor en los terrenos más lejanos, donde el sol y el frío del altiplano marcan a estos hijos de la madre tierra. De esta forma, mediante la transmisión oral, desde la conversación y el quehacer cotidiano, se han transmitido aprendizajes y valores relacionales del Suma Qamaña ${ }^{4}$.

Son importantes los ciclos que comprenden el tiempo y su transición, es así como la Pachamama (madre tierra), la Mama Paxi (madre luna) y el Tata Inti (padre sol) son relevantes en la cultura andina, ya que, gracias a ellos, es posible la existencia, pues el sol se desplaza por un universo que contiene la vida y este movimiento se representa como un ciclo vital: nacimiento, desarrollo, muerte y renacimiento (Gavilán y Carrasco 2009).

Los Aymara tienen un profundo respeto y un acompañamiento ritual o simbólico especial respecto de la naturaleza y creen que los eventos naturales son "puentes" divinos entre el cielo y la tierra (Valdivia 2006).

El concepto de salud, derivado de la cosmovisión y del Suma Qamaña, es central al momento en que las ciencias occidentales, en general, y la psicología, en particular, quieren conocer a la persona Aymara y trabajar con ella. Es por ello que es 
importante comprender que el concepto de salud para este pueblo se refiere a la salud del cuerpo, la mente y el espíritu en conjunto con el entorno presente y pasado y no como una performance de los programas de salud intercultural (Carreño y Freddi 2020). De este modo, la chacra y el ganado, la casa y la naturaleza, son parte esencial de la salud para la persona andina. Según los Yatiris $^{5}$, no solo los seres humanos pueden enfermarse, sino también los lugares y los espacios a causa de los espíritus extraños. Asimismo, tanto las personas como los lugares pueden y deben ser curados (Burman 2011).

Las festividades se orientan a celebrar la fertilidad como deseo de bienestar y abundancia, y a la muerte/vida en un permanente ciclo del devenir (Gavilán y Carrasco 2009). Cuando se hacen las ceremonias es necesario compartir la hoja de coca y el pusi con la madre tierra y con los Achachilas o cerros-antepasados protectores de la comunidad, en donde las relaciones son preponderantemente estrechas y complementarias.

La madre tierra tiene ciclos, épocas de siembra, cosecha, descanso, de remover la tierra y de fertilización natural. Así como el cosmos tiene ciclos, la historia tiene épocas de ascenso y descenso, la vida tiene épocas de actividad y pasividad (CAOI 2010). Como destaca Saavedra (2013), si en el mundo occidental se adoptara parte de la cosmovisión indígena se daría primacía a lo colectivo y se resolverían algunos problemas que son consecuencia del modelo de desarrollo occidental.

En general, en todas las festividades se pueden identificar los principios fundamentales del Suma Qamaña como ejes de la(s) interacción(es), por ejemplo, en la Muruña ${ }^{6}$ y otras festividades se entrega ganado como ofrenda. Las actividades de agricultura, ganadería y textilería son trabajos que se llevan a cabo principalmente en colectivo y hoy aún perduran inclusive en las ciudades (González C. y Carrasco, A. 2020).

\section{La mujer Aymara}

Para los Aymara la unidad mínima de organización social es la familia (Yampara et al. s. f.), la que está constituida por la unión Chacha-Warmi, quienes tienen que dar estabilidad al hogar.

Tradicionalmente, la Warmi cumple labores domésticas, pero hoy también se observa que, con el tiempo, las posibilidades de desarrollo para la mujer se han ido ampliando mediante el ingreso de algunas mujeres a la educación universitaria y el desarrollo de otros trabajos fuera de la casa y la comunidad. Actualmente, el rol de la mujer dentro de su comunidad es versátil y activo, lo que se puede observar, por ejemplo, en la participación dirigencial en sus comunidades, así como en ámbitos y espacios de representación política nacional e internacional. No solo demandan atención y respeto por los derechos colectivos como pueblos, sino también abogan por la defensa de sus derechos como mujeres (Pequeño et al. 2009). Esto es, tal vez, una materialización de lo que Carrasco y Gavilán (2014) denominan como una apertura de lo femenino para transgredir el orden social establecido. Está claro que la mujer Aymara ha salido del anonimato del hogar para ocupar un espacio en la comunidad, aportando al intercambio entre los diferentes pisos ecológicos, lo que invita inequívocamente a hablar de lo translocal de sus vidas, es decir, que ya no se circunscriben a lo que acontece entre los límites territoriales históricos urbano-rural (Carrasco y González 2014). El dinamismo que se observa en los roles estratégicos que asumen las mujeres en la reproducción de sus familias y comunidades es una de las principales consecuencias de los flujos de movilidad de las personas entre el altiplano/precordillera, valles y ciudades costeras, es así como se ha translocalizado la familia extensa Aymara (Álvarez 2017), por cuanto algunas mujeres Aymara viven no solo en una translocalidad constante, sino que también en una interculturalidad habitual, debido a que tienen una relación continua con diversos territorios (comunidades y ciudad).

\section{Warmis y sus relaciones sociales e institucionales}

La colonialidad y sus consecuencias históricas en América Latina y, por tanto, en la Región de Tarapacá, tiene matices propios, como la llamada chilenización en la que se usó a la escuela, al servicio militar, a Carabineros, a la Iglesia y a otras instituciones, como herramientas para chilenizar a los pueblos originarios con métodos y formas que de manera sincrética permanecen en los pueblos y ciudades como un proceso forzado para los Aymara y otros pueblos (Eriksson, 2016). Van Kessel (1992) explica cómo la tradición indígena incorporó el Evangelio, lo que para Gavilán y Carrasco (2009) se concibe como sincretismo religioso, es decir, una mezcla o yuxtaposición de las creencias indígenas 
y cristianas, porque existiría un dualismo: religión clandestina/religión oficial. La religiosidad, además de la Escuela, fueron y siguen siendo una institución del Estado nación de Chile para homogeneizar culturalmente a sus ciudadanos/as (Gavilán y Carrasco 2009), hoy por medio de la imposición de un determinado currículo de asimilación, el que facilita la reproducción de formas de discriminación no solo nacionalista sino que además de racial y étnica (Mondaca R., Zapata S. y Muñoz H. 2020).

Actualmente, las mujeres Aymara han tenido o tienen contacto con diversas instituciones como "CONADI ${ }^{7}$, MINSAL $^{8}$, INDAP $^{9}$, SERNATUR $^{10}$, PER TAMARUGAL ${ }^{11}$ ", entre otras. El acercamiento ha sido tanto para obtener información, capacitación y orientación para emprendimientos, como para la postulación de proyectos comunitarios, familiares e individuales, ayuda para organizarse en asociaciones y comunidades indígenas o simplemente para dar a luz a sus hijos/as (aunque la preferencia es el parto con partera), de esta forma, las vidas de las mujeres Aymara se han tejido y teñido de aspectos culturales occidentales e idiosincráticos.

\section{Metodología}

Estudiar el Suma Qamaña en estos tiempos permite reflexionar al considerar la memoria e historia del pueblo Aymara por siglos de relación entre el mundo indígena y el occidental. Esta investigación cualitativa, abordada desde el paradigma de la investigación indígena, considera las relaciones sociales de mujeres Aymara translocales de la Región de Tarapacá. La parte empírica de este estudio se realizó entre el primer semestre de 2018 y el primer semestre de 2019.

El paradigma de investigación indígena propone cuatro aspectos: Ontología, Epistemología, Metodología y Axiología, como elementos relacionados e indivisibles que se nutren y refieren mutuamente sin que exista una jerarquía entre ellos. La Ontología se contextualiza dentro de las cosmovisiones de cada pueblo, sin embargo, la conexión entre las diferentes cosmovisiones es la naturaleza relacional de la existencia y su enfoque holístico. La Epistemología incorpora sistemas de conocimiento indígena a la investigación y como guía del proceso del conocimiento a una red de relaciones interpersonales, intrapersonales, medioambientales y espirituales. La Axiología es de carácter contextual y relacional que se desarrolla bajo los principios de respeto, reciprocidad, y responsabilidad (propios de la cosmovisión) con todos los entes y relaciones del planeta; además considera la protección del conocimiento en favor de las poblaciones y reconoce la multiplicidad de subjetividades en toda índole. Finalmente, la Metodología, que en este caso no tiene el objetivo de explicar sino de aprender y entender las responsabilidades y las relaciones que los humanos establecen con el mundo y las relaciones que componen la totalidad (Arévalo 2013). Sobre estas bases está instalada la presente investigación.

\section{Participantes}

El estudio se enfocó en la Región de Tarapacá, específicamente, en seis mujeres pertenecientes a los siguientes pueblos: Chiapa, Miñe-Miñe, Cancosa, Ancuaque y Pisiga Centro, pertenecientes a las comunas de Huara, Pica y Colchane. Como criterios de selección se consideraron: a) Autoadscripción al pueblo Aymara; b) Mujer adulta (35-65 años); c) El tener una dinámica de vida translocal.

\section{Descripción del proceso de investigación}

Se realizó una revisión bibliográfica selectiva y rigurosa respecto de los objetivos de la investigación y con la información recolectada se construyó el marco teórico y conceptual. Paralelamente a la revisión bibliográfica, se elaboró una pauta temática amplia, que fue revisada por informantes claves y expertos del área, en ella participaron: el Yatichiri Hítalo Hidalgo, la psicóloga Aymara Yasmina Condori y Hans Gundermann, un destacado antropólogo. Tras realizar las modificaciones sugeridas, se realizó una primera entrevista, en la que se comprobó la factibilidad y viabilidad de la pauta elaborada. Seguidamente, se realizó el proceso de familiarización y vinculación con la comunidad y las participantes. Luego se realizaron las otras cinco entrevistas a mujeres Aymara.

Las entrevistas se iniciaron con un consentimiento oral (debido a que en el mundo Aymara la palabra manifestada de forma oral prevalece por sobre lo escrito). Las entrevistas fueron realizadas en el lugar en donde estaba cada una de las participantes. La información fue grabada en audios, transcrita y codificada, luego fue utilizada para hacer los análisis que constituyen los resultados de la presente investigación, después se efectuó la triangulación de los 
resultados con tres mujeres Aymara, caracterizadas por una alta pertinencia cultural ${ }^{12}$.

\section{Resultados}

El proceso de análisis de las entrevistas dio como resultado tres categorías constituidas por tres momentos identificados en los relatos de las participantes. El primer momento (M1) se destaca por una fuerte presencia del Suma Qamaña, el segundo momento (M2) se caracteriza por un distanciamiento con la comunidad y del Suma Qamaña, el tercer momento (M3) reconoce, principalmente, un reencuentro con el Suma Qamaña, la comunidad y la cosmovisión andina. Cada momento ha sido identificado en los relatos de las participantes y construidos a partir de las narrativas, recuerdos y relatos de ellas. Así, se describen los afectos, sentimientos, emociones y sensaciones, relacionadas a la experiencia de ser mujer Aymara translocal en la Región de Tarapacá.

En el M1 se comienza con las primeras experiencias significativas y recuerdos de la memoria personal y colectiva de las mujeres entrevistadas. El parto tradicional Aymara refleja los pilares de la cosmovisión andina, en la que cobra especial relevancia la organización comunitaria por sobre los sujetos, el contacto íntimo y armonioso con los elementos propios del entorno, así como el respeto por la integridad física y ética de sus integrantes, estos aspectos reflejan completamente el Suma Qamaña y la cosmovisión del pueblo Aymara, como lo señalan también Muñoz y Segovia (2002). La dimensión territorial que el nacimiento le otorga a la mujer, no solo en un gentilicio, también es una referencia a la comunidad. Basados en conocimientos que son transmitidos por las mujeres mayores de la comunidad a las mujeres que tienen su primer parto e incluso a los propios maridos y familiares, de quienes se espera una participación activa en los nacimientos siguientes. La mayoría de las madres de las participantes tuvieron más de un parto tradicional. Ejemplo de ello es Hantaturu quien indica que la abuela se preocupaba de alularla.

"Yo nací en Chiapa, porque mis padres son de ahî́" (...) "A todos los niños que nacían, mi abuela era de eso y preocupada protegiendo la mollerita con lanita de cordero, viendo el gorrito, alularla altiro a uno y a cuidarla a uno que no tiene que ver sol, en la sombra por lo general uno está en cuarto oscuro donde uno paría, eso lo que cuenta mi mamá" (Hantaturu, 28 de enero, 2019).

En el parto vivido de forma tradicional se genera un sentimiento de pertenencia al territorio, una identificación con el pueblo, y en los relatos de ese momento se denota una afectividad y una rememoranza elevada. Además, se puede percibir una relación directa entre esta afectividad y el respeto, la armonía y los otros principios del Suma Qamaña. Al nacer y vivir los primeros años en este estrecho vínculo con la tradición y la cosmovisión y vivir en esta comunidad, el estilo de vida comunitario las hace ser parte de este todo territorio-comunidad-cosmovisión.

En los relatos de vida de las participantes se pueden encontrar variadas referencias a este vivir en concordancia con el Suma Qamaña y sus principios desde que tienen algún recuerdo. Por ejemplo, Susana refiere que sus primeros recuerdos son en Aymara, porque es la lengua de su madre y abuela.

"Yo viví en la comunidad con las personas, con mi abuela, mi abuelo (...)" (Hantaturu, 28 de enero, 2019).

"Sé la lengua es que allá hablaba Aymara nomás con mi mamá y mi abuelita (...)" (Susana, 27 de febrero, 2019).

La lengua Aymara se presenta como un afecto que facilita la comunicación, el diálogo y, en consecuencia, provoca una mejor fluidez no solo en las relaciones sociales, sino que además con las entidades territoriales andinas.

Junto con la lengua, estas mujeres, desde muy temprana edad, tuvieron aprendizajes relacionados con la agricultura, la ganadería, la artesanía, el tejido y la cocina tradicional, todo ello inculcado con un profundo respeto hacia la naturaleza. Estas enseñanzas, principalmente, se transmiten de generación en generación por medio de sus familiares, incluso para las que nacen en la ciudad, estas enseñanzas están presentes en el seno familiar en el que existe una relación con el entorno, donde los mayores transmiten estos conocimientos a los demás por medio de la oralidad. Así es como Ancestral, pese a nacer en la ciudad, construye igualmente una identidad Aymara en comunidad.

"Me crié en la ciudad, muy lejos de la comunidad (...) Teníamos todos los elementos 
de una comunidad indígena acá y sobre todo de mi comunidad" (Ancestral, 12 de febrero, 2019).

"Aprendí de chiquitita a hilar, a sembrar, a lo que es pastoreo de animales ¿cierto? A todas las actividades que uno hacía allá (...) ¿las mamá qué nos dicen? Tenemos valores importantes que se nos dicen de chiquitita, que no debemos robar, que no debemos ser flojas, que debemos trabajar" (Susana, 27 de febrero, 2019).

Existe un gran afecto, sentimiento de pertenencia hacia el territorio y valoración de la naturaleza dotada de vida, a la que se la considera, respeta y aprecia, esto dado por la cosmovisión andina que trae consigo creencias, significados y símbolos inculcados por el entorno familiar y comunitario.

Hay un espacio temporal indefinido en la transición entre el M1 y el M2, en donde comienza un distanciamiento con la práctica de los principios del Suma Qamaña, principalmente porque pierde el sentido en grupos urbanos no Aymara o en la institucionalidad del país como la escuela. Este proceso se caracteriza por la movilidad de las mujeres o de sus familias hacia la ciudad.

En el M2 ocurre un distanciamiento territorial con el entorno social y comunitario Aymara, debido a la inserción de las instituciones estatales en el territorio Aymara, que genera un cambio estructural en la dinámica de la vida, además de la imposición de la nacionalidad chilena por sobre la comunidad. Así, el inicio de la etapa escolar marca el inicio de la transición. De la misma manera, la bajada a la ciudad de la familia, ya sea por una búsqueda del mejoramiento de las condiciones económicas o por educación, conlleva procesos de asimilación, adaptación y discriminación que presionan para dejar atrás los aprendizajes culturales en el trato con la alteridad.

"Te digo, desde los tres años mis padres se vinieron a Pozo y ya después a Iquique y ya nunca más tuve un convivir (...)" (Daniza, 4 de febrero, 2019).

Las narrativas personales de cómo vivieron el cambio desde el pueblo a la ciudad y cómo se alejaron del Suma Qamaña, evidencian procesos de adaptación y asimilación de la cultura occidental. Las participantes recuerdan sentir emociones negativas como tristeza, miedo y frustración, en esta adaptación a las costumbres chilenas propias de la vida urbana. Incluso, Hantaturu refiere haber sido medicada para sortear esto.

"Lloré todos los días (...) Después, empezaron a darme medicamentos (...) pero ellos no entendían cómo curar la pena también, porque se puede, porque nuestro cuerpo es fuerte $(. .$.$) fue muy traumático entonces$ comer comidas que tú no conocías (...)" (Hantaturu, 28 de enero 2019).

"Yo sufrí un tema de cambio de sitio, de mi vestimenta, desde mis ojotas ¿cierto? Cuando llego acá a la ciudad tuve que usar zapatos, se me llenaron los pies de ampollas (...)" (Susana, 27 de febrero, 2019).

La adaptación se les hizo compleja en la educación, vestimenta, salud y alimentación. Todo esto es descrito como un largo periodo de dificultades personales y de sufrimiento, por el distanciamiento con la comunidad y la ausencia del Suma Qamaña en las relaciones con los otros.

“Terminaba el colegio, mi papá llegaba a buscarme y me llevaba pa' los llamo (...) a ir a tejer y hacer todas las cosas que yo seguía haciendo (...) o sea yo nunca me quedé acá (...) apenas salía de vacaciones me iba a Colchane" (Susana, 27 de febrero, 2019).

De alguna manera, como en la vida de Susana, el Suma Qamaña estuvo presente gracias a sus padres, en las vacaciones y en sus recuerdos, ya que cuando ella se fue a la ciudad a estudiar, tuvo una relación directa con la ciudad, pero se mantuvo en conexión con el pueblo, porque sabía que la esperaban y que iba a regresar. La discriminación en las instituciones educativas estuvo presente y marcó de manera trascendental el vivir de estas mujeres, por su color de piel, condición social o apellido sufrieron de maltratos por parte de sus compañeros, como lo relata Daniza.

"De repente empieza un poco el bulling (...) empieza esta cosa que no sé si de rechazo (...) me decían 'paisana, que india tal por cual' (...) y te juro que a mí me dolió en el alma lo que me trató, así con insulto y 
groserías y lo único que atiné fue llorar, no aguanté más" (Daniza, 4 de febrero, 2019). "En la escuela me discriminaron por ser más morena, en un grupo todos eran más morenitos que yo, también me discriminaron por ser más blanca" (Ancestral, 12 de febrero, 2019).

La discriminación que más recuerdan es por el color de la piel, lo que se relaciona con varias investigaciones que indican la presencia de discriminación en el ámbito escolar chileno (UNICEF, 2004). El entorno escolar fue vivenciado como un contexto muy distinto y ajeno, que tenía exigencias, prejuicios y costumbres diferentes a lo conocido en el pueblo, en consecuencia, ellas experimentaron emociones desagradables como tristeza.

Estas experiencias vividas en la ciudad encuentran un correlato en la comunidad con la religión. Las Iglesias católica y protestante llegan para evangelizar y establecen templos en el mismo pueblo, de esta manera las creencias y costumbres del pueblo Aymara van dando paso a las enseñanzas de una Iglesia occidentalizada que no ve el mundo de la misma manera y que juzga la forma en que las comunidades viven, forzando desde hace ya mucho tiempo un sincretismo religioso, la Pastoral Andina, también, tiene una mixtura de cosmovisión y religión que atrae a los Aymara en la ciudad.

"Mis padres eran evangélicos y casualmente mi suegra, la familia de ella, también era evangélica" (Susana, 27 de febrero, 2019). "Yo era de la pastoral andina (...) hacía las preparaciones de la virgen de La Tirana (...) yo pertenecía a la iglesia con pertenencia cultural" (Hantaturu, 28 de enero, 2019).

Las instituciones mencionadas se instalaron físicamente y de forma permanente en las comunidades, lo que de acuerdo con las entrevistadas trajo consigo violencia, sufrimiento, tristeza y dolor. La religión tuvo la función de evangelizar, la educación formal de educar y Carabineros de Chile llegó con su fuerza a imponer el orden y seguridad.

"En Iquique había un hogar, porque yo llegué a un hogar a estudiar de allá" (Susana, 27 de febrero, 2019).

"Yo sufrí (...) Cuando llegaron a la comunidad, yo era niña y casi todas las niñas fueron violadas por los carabineros, entonces eso me marcó a mî" (Hantaturu, 28 de enero, 2019).

El modelo biomédico/biologicista que tiene el sistema estatal de salud, también promueve indirectamente un alejamiento del Suma Qamaña, ya que relativiza todas las creencias, conocimientos y costumbres del proceso salud-enfermedad Aymara, que existen desde antes de la creación del Estado. Las participantes, si bien nacieron bajo las costumbres del parto Aymara, refieren que para su trabajo de parto debieron acudir al hospital público, en sus relatos dan cuenta de una violencia obstétrica en controles de embarazos y partos, lo que evidencia una relación desarmoniosa, jerárquica, de abuso de poder y violencias, es decir, sin presencia del Suma Qamaña. Esto les generó a ellas emociones y sentimientos negativos, desconfianza y rechazo hacia el sistema de salud pública.

"En el hospital te amarran y hay que estar estirado con dolor (...) En la casa no po, le mantean, le mantean y nace nomás la guagua" (Clara, 23 de febrero, 2019).

"Fui con pérdida de líquido el día anterior a tener a mi guagüita y me trataron muy mal en el hospital, entonces decidí tenerla en la clínica" (Ancestral, 12 de febrero, 2019).

Durante el M2 todas las mujeres, por algún motivo, se alejan de sus comunidades, esto significa la búsqueda de nuevas formas de ser para adaptarse a este nuevo entorno sociocultural, lo que les significa una reestructuración identitaria y la consiguiente revalorización de sus grupos de pertenencia.

Hacia el fin de la educación formal, ya sea el fin del colegio o el fin de los estudios superiores, las mujeres refieren comenzar a interactuar con otros Aymara en la ciudad y esto marca un periodo de reencuentro con la cosmovisión y el Suma Qamaña, este reencuentro caracteriza al M3. Socializar con estas personas, les permitió retornar a sus territorios, conectarse con los significados atribuidos a sus primeras experiencias, buscar sus raíces, su cultura, costumbres y tradiciones, lo que genera una modificación en la percepción de cada persona y se resignifican algunos recuerdos, reviviendo experiencias del M1.

Hantaturu refiere que después de haber tenido una ruptura de vida en pareja, se fue con sus hijos 
a Tarapacá e inició un trabajo relacionado con la cocina tradicional, valoró la presencia de su comunidad y viceversa. Luego, fue reconocida a nivel mundial como cocinera tradicional y, también, por su práctica espiritual de Yatiri en los pueblos y en la ciudad. Por su parte, Clara siempre sostuvo algún tipo de vínculo con su comunidad, pero, igualmente, refiere haber tenido un reencuentro mediante sus trabajos en la agricultura y la ganadería. Susana, también, relata que en el trabajo con otras mujeres en artesanía con productos textiles Aymara, se reencontró con sus raíces y sus recuerdos de infancia de una comunidad fuerte y una cosmovisión distinta de lo aprendido en el colegio, que adquirió mayor sentido para ella y la ayudó a promover el turismo en la localidad. Ancestral cuando comenzó a buscar sus orígenes y empezó a estudiar logró integrar sus aprendizajes y ponerlos a disposición de la comunidad, actualmente junto con su marido defienden desde una perspectiva sociojurídica a los pueblos originarios. Finalmente, Daniza cuando comenzó su matrimonio con un hombre Aymara, pasó a formar parte de su familia y de sus costumbres, se vinculó a la ganadería, más adelante comenzó a trabajar en el ámbito turístico con la comunidad y, posteriormente, llegó a asumir un cargo de representatividad comunitaria.

"Cuando fui al carnaval, el haber hecho la entrada, el haber acompañado a los tíos, el escuchar los tonos (...) me gustó, porque de verdad que se genera un compartir bien especial (...) A los diecinueve años cuando yo llego a Ancuaque, justamente en la familia de mi pareja tienen ganado" (Daniza, 4 de febrero, 2019).

"Hay mucha gente que es de ahí, porque es del tronco familiar, además el apellido que yo tengo es uno de los principales apellidos de la comunidad" (Ancestral, 12 de febrero 2019).

En este momento (M3) se forman vínculos grupales fuertes, ya sea en la participación en asociaciones indígenas de artesanas, en la comunidad, en el grupo de jóvenes y con otras mujeres de pueblos originarios, lo que les ha permitido relacionarse, compartir, conocer y desarrollarse.

"Trabajé como 4 o 5 años con las artesanas hasta formar una cooperativa de mujeres, ya entonces ahora estamos trabajando (...)" (Susana, 27 de febrero 2019).

"El año 2000, la comunidad de Ancuaque permite la participación de mujeres a lo cual ya puede acceder a cargos" (Daniza, 4 de febrero, 2019).

Estas relaciones que las llevan al reencuentro comienzan en la adolescencia y en la primera adultez, periodos en que la mayoría de las entrevistadas se relacionan con su territorio y pasan a identificarse con su comunidad de origen o con la comunidad de su esposo o pareja, experimentan sentimientos, sensaciones, emociones agradables que las conectan con su niñez, así también, hay aceptación de parte del grupo en el que se desenvuelven. No obstante, también, experimentan sentimientos desagradables como la amenaza y el peligro, por ejemplo, con la intromisión de las empresas mineras que generan diversos impactos, lo que se manifiesta en angustia y preocupación, estados de ánimo que se expresan en somatizaciones corporales, como dolor de estómago y malestar en el cuerpo de las mujeres Aymara.

"Lo que pasa las descompone totalmente, su cuerpo, en el sentido de que todo nuestro sentir se manifiesta biológicamente, entonces era como un dolor de guata o como la angustia (...) Se imagina toda esta devastación, se imagina el cerrito contaminado, el agüita contaminada" (Ancestral, 12 febrero, 2019).

\section{Conclusión}

Por medio de los relatos de las participantes se han podido identificar tres momentos distintos y dinámicos de presencia/ausencia del Suma Qamaña. El primer momento (M1) comienza con el nacimiento y se caracteriza por el aprendizaje y el respeto de las costumbres Aymara, Suma Qamaña y cosmovisión que son basales en la comprensión del mundo, lo que da un fuerte sentido de pertenencia y presencia de afectos positivos hacia el lugar de nacimiento, la familia y la comunidad. El segundo momento (M2) se inicia con una transición entre grupos sociales, por la llegada de instituciones estatales al pueblo o la migración a la ciudad, lo que genera un distanciamiento del Suma Qamaña, del territorio y del entorno social Aymara. Esto genera un cambio estructural en la dinámica de 
vida de las participantes, quienes se distancian de su idiosincrasia y sufren una asimilación cultural, una restructuración identitaria, emociones negativas, violencia, discriminación, bullying, rechazo y confusiones asociadas a la jerarquización de los grupos de pertenencia. Las relaciones interpersonales se ven fuertemente influidas por la percepción del "otro" en la relación con personas no Aymara y mestizos. El tercer momento (M3) puede entenderse como un reencuentro con el Suma Qamaña, con el territorio y con lo Aymara en general. Ocurre con la entrada al trabajo en las comunidades, por el vínculo matrimonial con un hombre Aymara o por la descendencia familiar, al participar de faenas comunitarias como limpiar canales, bañar ganado o por medio de la agricultura, donde trabajan la tierra sembrando quinua, papas, hortalizas y otros. También, ocurre en la textilería tradicional con otras mujeres indígenas, en el desarrollo del turismo comunitario en el altiplano, en la realización de talleres con temáticas de derechos indígenas con otros comuneros y en las labores de representación comunitaria.

En este reencuentro (M3) existe un retorno al origen, desde la socialización con pares Aymara se construyen y reconstruyen afectos y sentimientos de pertenencia, donde (re)encuentran aceptación, así como apoyo emocional y surge la conexión con los recuerdos de la niñez que se resignifican y estas memorias ayudan a fortalecer las relaciones sociales. De esta experiencia se ha aprendido cuándo, cómo y con quiénes se puede interactuar con y desde el Suma Qamaña, es así como queda reservado para las relaciones con pares y otros quienes demuestren respeto por los principios relacionales, la cosmovisión y la cultura Aymara.

Es posible señalar que, a futuro, pueden emerger otros momentos en las vidas de estas mujeres, debido a que sus lazos con el Suma Qamaña pueden variar, ya que ellas, así como sus vidas, son dinámicas. En las narrativas personales de las seis mujeres entrevistadas puede visualizarse que se encuentran en el tercer momento, en el que se relacionan desde el Suma Qamaña con sus pares y de igual manera se mueven hábilmente en el mundo de la ciudad. Sienten pertenencia al pueblo indígena, orgullosas de ser Aymara, conectadas en armonía con la naturaleza, se identifican con el trabajo, el emprendimiento y la cosmovisión andina, además, piensan que es necesario construir identidad mediante la participación y ser activas en el asumir roles y en la toma de decisiones.

\section{Agradecimientos}

Agradecemos al Pueblo Aymara por el espacio y confianza brindada y, en especial, a la participación de las Kullallas ${ }^{13}$ que fueron parte de este proceso de estudio, también, a quienes nos apoyaron e inspiraron para escribir esta investigación, ya que sin ellos/as no hubiera sido posible.

Finalmente, dedicamos esta investigación a los Pueblos Originarios, a las comunidades de las Warmis que participaron en este estudio, a nuestras familias y a quienes nos brindaron ayuda y apoyo incondicional.

\section{Referencias Citadas}

Álvarez Díaz, A.

2017 Nuevos escenarios de género entre los Aymaras del norte Chileno. 42(July), 408-416.

Álvarez González, F. J.

2011 "El buen vivir un paradigma anticapitalista". Pacarina del sur: Revista de pensamiento crítico latinoamericano, 16 (Modernidades alternativas), 1-36. http://www.pacarinadelsur.com/

Arévalo, G.

2013 "Reportando desde un frente decolonial: la emergencia del paradigma indígena de investigación". Experiencias, luchas y resistencias en la diversidad y multiplicidad, 51-78.

Burman, A.

2011 Yatiris en el siglo XXI. El conocimiento, la política y la nueva generación. Nuevo mundo mundos nuevos, 0-16. https://doi.org/10.4000/nuevomundo.61331
Carrasco Gutiérrez, A. M., y González Cortez, H.

2014 "Movilidad poblacional y procesos de articulación rural-urbano entre los aymara del norte de Chile". Si Somos Americanos, 14(2), 217-231. https://doi.org/10.4067/ s0719-09482014000200009

Carreño Calderón, A., y Freddi, A.

2020 "Performativizar la democracia: salud y enfermedad como espacios de acción política entre los Aymaras del norte de Chile". Diálogo Andino, (62), 31-40.

Díaz Araya, A., y Tapia Ladino, M.

2013 Los aymaras del norte de Chile entre los siglos. 181-196.

Eriksson, P.

2016 Discriminación hacia los aymaras en el caso jurídico chileno de Gabriela Blas.

Gavilán, V. V., y Carrasco, A. M. G.

2009 "Festividades andinas y religiosidad en el Norte Chileno". Chungara, 41(1), 101-112. https://doi.org/10.4067/ S0717-73562009000100007 
Giraldo, O. F.

s. f. Utopías en la era de la supervivencia una interpretación del buen vivir.

González Carrasco, D. A., y Carrasco, A. M.

2020 "Memory and identity. The aimara textile tradition in northern Chile and the built space". Diálogo Andino (63), 91-100.

Guarachi Ramos, R., y Guarachi Ramos, R.

2017 "El ayni, un sistema de vida ancestral" (Hoy por ti mañana por mí). Rev Inv Sci [online], vol. 6, n. 1, pp. 03-25 . Disponible en: $<\mathrm{http}: / / \mathrm{www}$. revistasbolivianas.org.bo/scielo. php?script=sci_arttext\&pid=S2313-02292017000100001\&ln $\mathrm{g}=\mathrm{es} \& \mathrm{nrm}=\mathrm{iso}>$. ISSN 2313-0229.

Gudynas, E.

2009 "La dimensión ecológica del buen vivir: entre el fantasma de la modernidad y el desafío biocéntrico". OBETS. Revista de Ciencias Sociales. 4. 10.14198/OBETS2009.4.05.

Gudynas, E., y Acosta, A.

2011 "El buen vivir más allá del desarrollo". Quehacer, 181, 70-81. http://www.dhl.hegoa.ehu.es/recursos/928\%5Cnhttp:// www.desco.org.pe/node/6808

Gundermann Kroll, H., y González Cortez, H.

2008 "Pautas de integración regional, migración, movilidad y redes sociales". En Los Pueblos Indígenas de Chile. Universum (Talca), 23(1), 82-115. https://dx.doi.org/10.4067/ S0718-23762008000100006.

Gundermann Kröll, H.

2018 "Los pueblos originarios del norte de Chile y el Estado". Diálogo Andino (55), 93-109.

Huanacuni Mamani, F.

2010 "Buen Vivir/Vivir Bien Filosofía, políticas, estrategias y experiencias regionales andinas". En Journal of Chemical Information and Modeling (Vol. 53, Número 9). https:// doi.org/10.1017/CBO9781107415324.004

Ibacache Burgos, J., Morros Martel, L., y Trangol Namuncura, M. 2002 Salud mental y enfoque socio espiritual-psico-biológico. Una aproximación ecológica al fenómeno de la saludenfermedad desde los propios comuneros y especialistas terapéuticos mapuche de salud.

Kessel, J. J. M. M.

1980 Holocausto al progreso: Los aymaras de Tarapacá. Centrum voor studie en documentatie van Latijns-Amerika.
Mondaca-Rojas, C., Zapata-Sepúlveda, P., y Muñoz-Henríquez, W. 2020 "Historia, nacionalismo y discriminación en las escuelas de la frontera norte de Chile". Diálogo Andino (63), 261-270.

Muñoz, M. y Segovia M.

2002 Propuesta psicoprofiláctica en la atención de pacientes embarazadas aymaras, tesis licenciatura en psicología de la Universidad de Tarapacá.

Pequeño, A.; Cumes, A.; Méndez Torres, G.; Flores Carlo, A.; Calfio Montalva, M.; Cuminao Rojo, C.; Lavinas Picq, M.; Pequeño Bueno, A.; Segura Villalva, M.; Guzmán Gallangos,

F.; Pérez Moscoso, M. S. y Mercedes Duarte, J.

2009 "Participación y políticas de mujeres indígenas en contextos latinoamericanos recientes". En Participación y políticas de mujeres indígenas en contextos latinoamericanos recientes.

Restrepo, E., y Rojas, A.

2010 "Inflexión decolonial: fuentes, conceptos y cuestionamientos". En Journal of Chemical Information and Modeling (Vol. 53, Número 9). https://doi.org/10.1017/ CBO9781107415324.004

Ribadeneira Aroca, K.

2020 "Buen vivir: críticas y balances de un paradigma social en construcción". Diálogo Andino (62), 41-51.

Rodríguez, A., y Unceta Satrutegui, K.

2016 Teoría y práctica del Buen Vivir: Orígenes, debates conceptuales y conflictos sociales. El caso de Ecuador. Tesis doctoral, 422. https://doi.org/10.1017/CBO9781107415324.004

Tuhiwai Smith, L.

2016 A descolonizar las metodologias investigacion y pueblos indígenas. LOM (ed.).

\section{UNICEF}

2004 "Informe anual de actividades 2004-Chile".

Valdivia, M. P.

2006 "Cosmovisión Aymara y su aplicación práctica en un contexto sanitario del norte de Chile". Revista de Bioética y Derecho, 7(19), 1-305.

Vera Noriega, J. Á., y Valenzuela Medina, J. E.

2012 "El concepto de identidad como recurso para el estudio de transiciones". Psicologia e Sociedade, 24(2), 272-282. https://doi.org/10.1590/S0102-71822012000200004

Yampara, S., Torres, M., y Mamani, S.

s.f. Uraq-pacha utan utjawi/qamawi. Cosmovisión territorial ecología y medio ambiente.

\section{Notas}

1 Desde la mirada del pueblo Aymara no existe dicotomía entre sujeto/ objeto. Por lo que hay una relación directa con la naturaleza, el cosmos y las personas donde todos tienen un valor o vida y un espíritu.

2 Ayni andino significa que, cada acto o actividad de una persona condiciona (voluntariamente) o es consecuencia del acto de otra persona (Guarachi y Guarachi 2017), o sea ayudarse mutuamente, intercambio que exige reciprocidad estricta, suele llevarse la contabilidad de Aynis prestados o recibidos, existen diversos como, por ejemplo: en trabajos agrícolas, el intercambio de regalos o ayudas en alimentos, bebidas, Con ocasión de matrimonios, al construir casa nueva, para cumplir cargos comunitarios, etcétera.

3 Mujer Aymara translocal, dinámica de vida que no se acentúa en un solo territorio o piso ecológico sino que tiene una constante movilidad que la llevan a desarrollar diversas prácticas ancestrales y otras propias de la sociedad occidental.

4 Suma Qamaña en la lengua materna Aymara, se traduce al español como "buen vivir" o "vivir bien" (Huanacuni 2010) y el significado sería Suma: plenitud, sublime, excelente, magnífico, hermoso y Qamaña: vivir, convivir, estar siendo, ser estando.

5 En la sociedad Aymara existen muchos términos para referirse a las personas que son especialistas en rituales y curaciones. A parte de la variedad de términos en castellano para nombrar a esos especialistas (por ejemplo "curandero", "espiritista", "maestro" y el término despectivo "brujo") los términos más comunes son yatiri, ch'amakani, qulliri, y amawt'a (véase más en Burman 2011). Y son quienes 
tienen el saber médico andino, junto con parteras y compositores de huesos, que juegan un rol fundamental en el mundo andino.

$6 \quad$ Los padres de familia presentan pública y oficialmente al nuevo hijo a la comunidad y la sociedad Aymara para ser conocido y reconocido como su nuevo integrante y la familia extensa Aymara, la comunidad, reconoce oficialmente al nuevo hijo como miembro activo de ellas. Este proceso que se da simultánea y espontáneamente es el inicio de la inserción del varón o la mujer a la sociedad Aymara por medio de los padrinos.
Corporación Nacional de Desarrollo Indígena.

Ministerio de Salud.

Instituto de Desarrollo Agrícola.

Servicio Nacional de Turismo.

1 Programa Estratégico Regional.

12 Yasmina Condori Tocale, Bárbara Quenaya Montecinos y Miriam Colque Mamani.

13 En Aymara significa hermana, se utiliza esta palabra para referirnos a las Mujeres o Warmis que participaron de esta investigación debido a la confianza y cercanía sembrada. 